\title{
Synthesis of Highly Refractive and Transparent Polyimides Derived from 4,4'-[ $p$-Sulfonylbis(phenylenesulfanyl)]diphthalic Anhydride and Various Sulfur-containing Aromatic Diamines
}

\author{
By Yasuo SUZUKI, Jin-gang LIU, Yasuhiro NAKAMURA, Yuji SHIBASAKI, Shinji ANDo, and Mitsuru UEDA*
}

\begin{abstract}
Highly refractive and transparent polyimides (PIs) have been developed. The PIs were prepared from a para-substituted sulfonyl-bridged dianhydride, $4,4^{\prime}$-[ $p$-sulfonylbis(phenylenesulfanyl)]diphthalic anhydride ( $p$-DPSDA) and various sulfurcontaining aromatic diamines including 4,4'-thiobis[( $p$-phenylenesulfanyl)aniline] (3SDA), 4,4'-sulfonylbis[( $p$-phenylenesulfanyl)aniline] (BADPS), and 2,7-bis(p-aminophenylenesulfanyl)thianthrene (APTT) by employing a two-step polycondensation procedure. The PIs showed excellent thermal stabilities with $5 \%$ weight loss temperatures $\left(T_{\mathrm{d}}{ }^{5}\right)$ exceeding $470{ }^{\circ} \mathrm{C}$ in nitrogen and the glass transition temperatures $\left(T_{\mathrm{g}} s\right)$ higher than $208^{\circ} \mathrm{C}$. The PI films exhibited good optical transmittances exceeding $85 \%$ at $450 \mathrm{~nm}$ and high refractive indices of $1.7169-1.7420$ at $632.8 \mathrm{~nm}$ that are almost same as those of the PIs derived from 4,4'-[m-sulfonylbis(phenylenesulfanyl)]diphthalic anhydride ( $m$ DPSDA). The para-substituted electron-withdrawing sulfonyl moiety improves the transparency but lowers the refractive index. In addition, very small birefringence $(\Delta n)$ of $0.0065-0.0093$ was obtained for the PIs.

KEY WORDS: Sulfur-containing Polyimide / High Refractive Index / Transparency / Thermal Stability /
\end{abstract}

Polyimides (PIs) are a class of polymers extensively used in microelectronics because of their outstanding key properties such as high thermal stabilities, chemical resistance, and good mechanical and excellent electrical properties. ${ }^{1}$ They are used as interlayer dielectrics in integrated circuit fabrication. Recently, high refractive index PIs are increasingly noticed for microlens components for charge coupled device (CCD) or complementary metal oxide semiconductor (CMOS) image sensors because of their excellent properties described above and inherent high refractive index. ${ }^{2}$ Chen et al. prepared high refractive index aminoalkoxysilane-capped pyromellitic dianhydride (PMDA)titania hybrid optical thin films from PMDA, aminopropyltrimethoxysilane, and titanium (IV) isopropoxide via a sol-gel process. The refractive indices of these hybrid optical thin films were in the range of 1.567 to 1.780 depending on the titania contents. ${ }^{3}$ The syntheses of similar PIs/titania hydrid thin films were also reported in several papers. ${ }^{4,5}$ However, high refractive index PIs for microlens are required to have a good pattern formability by the conventional photolithography technique as well as low birefringence $(\Delta n)$, good transparency in the visible light region, and high thermal stability.

Based on these backgrounds, we have been interested in developing practical high- $n$ polymers, sulfur-containing PIs, and reported several PIs containing thioether linkages, either linear $^{6,7}$ or cyclic. ${ }^{8,9}$ Refractive indices as high as 1.76 at the wavelength of $632.8 \mathrm{~nm}$, and in-plane/out-of-plane birefringences lower than 0.01 have been successfully achieved. ${ }^{9}$ For fabricating optical devices, optical transparency might be one of the most serious obstacles for high- $n$ PIs. The formation of intermolecular or intramolecular charge transfer complexes (CTCs) between the electron-donating diamine moiety and the electron-accepting dianhydride moiety often results in the deep coloration of the PI films in the visible light regions. ${ }^{10}$ To remedy this problem, we reported highly refractive and transparent PIs derived from 4,4' - $m$-sulfonylbis(phenylenesulfanyl)]diphthalic anhydride (mDPSDA) and various sulfurcontaining aromatic diamines. ${ }^{11}$ The average refractive index $\left(n_{\mathrm{av}}\right)$ measured at $632.8 \mathrm{~nm}$ range from 1.7162 to 1.7432 depending on the different sulfur contents of PIs, and the metasubstituted electron-withdrawing sulfonyl moiety endowed PI films with good optical transparency. The optical transmittances of the PI films at $450 \mathrm{~nm}$ are higher than $85 \%$ for the thickness of $c a$. $10 \mu \mathrm{m}$.

As our continuous efforts to develop PIs with high refractive indices, combined with low birefringence, high thermal stability, and optical transparency, this paper reports the synthesis and properties of PIs from $4,4^{\prime}-[p$-sulfonylbis(phenylenesulfanyl)]diphthalic anhydride ( $p$ DPSDA) and various sulfur-containing diamines. Although the synthesis of PIs from $p$ DPSDA and aromatic diamines has been reported, their optical properties have not been studied. ${ }^{12}$ The intramolecular CT could be arisen from the contiguous (amine) phenyl donor/ imide acceptor fragments on the same chain, and the intermolecular CT could be arisen from a "mixed layer" configuration between the (amine) phenyl and imide groups of neighboring chains. Thus, a bulky sulfony moiety should reduce both the contiguous interaction between (amine) phenyl donor/imide acceptor fragments and the formation of a "mixed layer" configuration between the (amine) phenyl and imide groups of neighboring chains, ${ }^{13}$ and is expected to endow PIs with high transparency in a wide range in the visible region. On the other hand, a strong electron-withdrawing sulfonyl group 
increases the formation of intermolecular or intramolecular CTCs. In particular, the introduction of a sulfonyl unit at para position compared to at meta position effectively increases the electron-accepting ability, which may induce a decrease in transparency. Thus, it is interesting to shed light on the effects of a bulky and strong electron-withdrawing sulfonyl group at para position to optical and thermal properties of the resulting PIs. The structure-property relationships of the PIs derived from para-sulfonyl substitute dianhydride are discussed with comparing those of the corresponding PIs derived from metasulfonyl substitute dianhydride.

These results indicate the PIs derived from $p$ DPSDA have nearly $30^{\circ} \mathrm{C}$ higher $T_{\mathrm{g}} s$ than those of the corresponding PIs derived from $m$ DPSDA because a $p$-substituted sulfonyl linkage gives the more rigid PIs compared to the PIs having $m$-substituted sulfonyl linkage, which decreases the mobility of polymer chains at elevated temperatures.

\section{EXPERIMENTAL}

\section{Materials}

4,4'-Dichlorodiphenylsulfone (TCI, Japan), sodium monohydrogensulfide $n$-hydrate $\left(\mathrm{NaSH} \cdot n \mathrm{H}_{2} \mathrm{O}\right)$ and 4-bromophthalic anhydride (TCI, Japan) were used as received. $N$-Methyl-2pyrrolidinone (NMP, Wako, Japan) and $N, N$-dimethylformamide (DMF, Wako, Japan) were purified by vacuum distillation over $\mathrm{CaH}_{2}$ prior to use. 4,4'-Thiobis[( $p$-phenylenesulfanyl)aniline] (3SDA), ${ }^{7}$ and 2,7-bis ( $p$-aminophenylenesulfanyl)thianthrene $(\mathrm{APTT})^{9}$ were synthesized according to our previous work. 4,4'-Sulfonylbis[( $p$-phenylenesulfanyl)aniline] (BADPS) was synthesized according to the literature. ${ }^{12}$ Diphenylsulfone-4,4'-dithiol (1) was prepared from 4,4'-dichlorodiphenylsulfone and sodium monohydrogensulfide $n$ hydrate according to the procedure in the literature. ${ }^{14}$

\section{Synthesis of pDPSDA}

A two-necked $100 \mathrm{~mL}$ flask equipped with a magnetic stirrer, a nitrogen inlet, and a condenser was charged with a mixture of 1 (2.12 g, $7.5 \mathrm{mmol})$, 4-bromophthalic anhydride (3.75 g, $16.5 \mathrm{mmol})$, anhydrous $\mathrm{K}_{2} \mathrm{CO}_{3}(2.28 \mathrm{~g}, 16.5 \mathrm{mmol})$, and freshly-distilled DMF $(25 \mathrm{~mL})$. The mixture was heated to $120^{\circ} \mathrm{C}$ in nitrogen for $12 \mathrm{~h}$. Then, the mixture was cooled to room temperature, and the white solid was collected by filtration, and dried in vacuo at $160^{\circ} \mathrm{C}$ for $3 \mathrm{~h}$. The obtained white powder was boiled with concentrated hydrochloric acid $(50 \mathrm{~mL})$ for $3 \mathrm{~h}$. After the mixture was cooled to room temperature, the white solid (tetra-acid) was collected by filtration and washed thoroughly with cold water. The obtained solid was recrystallized from acetic anhydride to afford the dianhydride $p$ DPSDA as pale-yellow powder. Yield: $2.12 \mathrm{~g}$ (49\%). Mp: $230-232{ }^{\circ} \mathrm{C}$ (lit. ${ }^{12}$ 230-232 ${ }^{\circ} \mathrm{C}$ ). FT-IR (KBr, $\left.\mathrm{cm}^{-1}\right)$ : $1855(\mathrm{C}=\mathrm{O}), 1778(\mathrm{C}=\mathrm{O}), 1315(\mathrm{~S}=\mathrm{O}), 1253$ (Ar-S$\mathrm{Ar}), 1153(\mathrm{~S}=\mathrm{O}) .{ }^{1} \mathrm{H}$ NMR $(300 \mathrm{MHz}, \mathrm{DMSO}-d 6, \mathrm{ppm}): 8.06-$ 7.99 (m, 6H), 7.96-7.94 (s, 2H), 7.90-7.85 (d, 2H), 7.69-7.64 (d, $4 \mathrm{H})$. $\mathrm{E}_{\mathrm{LEM}}$. $\mathrm{A}_{\mathrm{NAL}}$. Calcd. For $\mathrm{C}_{28} \mathrm{H}_{14} \mathrm{O}_{8} \mathrm{~S}_{3}$ : C, 58.53\%; H, $2.46 \%$. Found: C, $58.05 \%$; H, $2.75 \%$.

\section{Synthesis of PI}

The general polycondensation procedure can be illustrated by the synthesis of PI-1 as follows. To a $30 \mathrm{~mL}$ two-necked flask equipped with a mechanical stirrer, a nitrogen inlet, and a cold water bath was added 3SDA $(0.433 \mathrm{~g}, 1 \mathrm{mmol})$ and freshly-distilled NMP (3.00 g). A clear diamine solution was obtained after stirring for $30 \mathrm{~min}$. Then, DPSDA $(0.575 \mathrm{~g}$, $1 \mathrm{mmol}$ ) was added in three portions to the stirred solution, followed by washing with additional NMP (1.03 g). The solid content of reaction mixture was adjusted to $20 \%$ by weight at the same time. The reaction mixture was stirred in nitrogen at room temperature for $24 \mathrm{~h}$ to afford a viscous pale-yellow solution.

The purified poly(amic acid) (PAA) solution was spincoated on a silicon (Si) wafer or quartz substrate, and the thickness was controlled by regulating the spinning rate. The thickness of the specimen for Fourier transform infrared (FTIR) and ultraviolet-visible (UV-vis) measurements was controlled to be approximately $10 \mu \mathrm{m}$, and the thickness of the specimen to be used for measuring thermal properties was adjusted to be $30-50 \mu \mathrm{m}$. The PI-1 film was obtained by thermally curing the PAA solution in an oven at 80, 150, 250, and $300{ }^{\circ} \mathrm{C}$ for $1 \mathrm{~h}$ each under nitrogen. The PI-1 film, which was pale-yellow in color at the thickness of $10 \mu \mathrm{m}$, was obtained by immersing the Si wafer in warm water.

The other PI films were prepared by a similar procedure described above, except that 3SDA was replaced by BADPS (PI-2), or APTT (PI-3), respectively.

\section{Measurements}

The ${ }^{1} \mathrm{H}$ and ${ }^{13} \mathrm{C}$ NMR spectra were recorded on a Varian Mercury 300 spectrometer using $\mathrm{CDCl}_{3}$ or DMSO- $d_{6}$ as solvent and tetramethylsilane as reference. The spectra of ${ }^{13} \mathrm{C}$ DEPT-135 (Distortionless Enhancement by Polarization Transfer) experiment were taken by using DMSO- $d_{6}$ as the solvent. Inherent viscosity was measured using an Ubbelohde-viscometer with a $0.5 \mathrm{~g} / \mathrm{dL}$ NMP solution at $30^{\circ} \mathrm{C}$. FT-IR spectra were obtained with a Horiba FT-120 Fourier transform spectrophotometer. UV-vis spectra were recorded on a Hitachi U-3210 spectrophotometer at room temperature. PI films were dried at $100^{\circ} \mathrm{C}$ for $1 \mathrm{~h}$ before testing to remove the absorbed moisture. Thermogravimetric analysis (TGA) was recorded on a Seiko TG/DTA 6300 thermal analysis system at a heating rate of $10^{\circ} \mathrm{C} / \mathrm{min}$ in nitrogen. Differential scanning calorimetry (DSC) was performed on a Seiko DSC 6300 at a heating rate of $10^{\circ} \mathrm{C} / \mathrm{min}$. Dynamic mechanical thermal analysis (DMA) was performed on PI film specimens ( $30 \mathrm{~mm}$ long, $10 \mathrm{~mm}$ wide, and 50-60 $\mu \mathrm{m}$ thick) on a Seiko DMS 6300 at a heating rate of $2{ }^{\circ} \mathrm{C} / \mathrm{min}$ with a load frequency of $1 \mathrm{~Hz}$ in air. The glass transition temperature $\left(T_{\mathrm{g}}\right)$ was determined as the peak temperature of the loss modulus $\left(E^{\prime \prime}\right)$ plot.

The in-plane $\left(n_{\mathrm{TE}}\right)$ and out-of-plane $\left(n_{\mathrm{TM}}\right)$ refractive indices of PI films were measured with a prism coupler (Metricon, model PC-2000) equipped with a He-Ne laser light source (wavelength: $632.8 \mathrm{~nm}$ ). The polarization of the incident light guided from a linearly polarized He-Ne laser was controlled by 
inserting a half-waveplate in the light path. The prism attachable to the surface of PI films was made of a single crystal of gallium-gadolinium-garnet (GGG). The birefringence $(\Delta n)$ was calculated as a difference between $n_{\mathrm{TM}}$ and $n_{\mathrm{TE}}$. The average refractive index $\left(n_{\mathrm{av}}\right)$ was calculated according to equation (1):

$$
n_{\mathrm{AV}}=\sqrt{\left(2 n_{\mathrm{TE}}^{2}+n_{\mathrm{TM}}^{2}\right) / 3}
$$

\section{DFT Calculation}

The refractive indices of the aromatic PIs synthesized in this study were calculated on the base of Lorentz-Lorenz theory as reported previously. ${ }^{6}$ One-electron transition energies and the corresponding oscillator strengths of the PIs were also calculated using the time-dependent density functional theory (TD-DFT) to predict the optical absorption in the UV-visible region. ${ }^{15}$ The $6-311 \mathrm{G}(\mathrm{d})$ basis set was used for geometry optimizations under no constraints, and the $6-311++G(d, p)$ was used for calculations of linear polarizabilities, transition energies, and oscillator strengths. The three-parameter Beckestyle hybrid functional (B3LYP) was adopted as a function and all the calculations were performed using the software package of Gaussian-03 (Rev.C02 and D01). A typical packing coefficient $\left(K_{\mathrm{p}}\right)$ of 0.60 was used for evaluating the intrinsic molecular volumes of models to predict the refractive indices. ${ }^{16}$

\section{RESULTS AND DISCUSSION}

\section{Synthesis of Monomer}

As Ding et al., prepared $p$ DPSDA from 4-chlorophthalic anhydride and $\mathbf{1}$ in the presence of triethylamine in $\mathrm{N}, \mathrm{N}$ dimehylacetamide at $60{ }^{\circ} \mathrm{C}$, we applied their method to prepare $p$ DPSDA. The yield, however, was so low. Thus, we referred the method to prepare $m$ DPSDA, i.e., $p$ DPSDA was prepared from 4-bromophthalic anhydride and $\mathbf{1}$ in the presence of anhydrous potassium carbonate in DMF at $120^{\circ} \mathrm{C}$ for $12 \mathrm{~h}$; followed by dehydration with acetic anhydride (Scheme 1). This procedure has been well established in the literature for bis(ether anhydride) or bis(thioether anhydride) synthesis. ${ }^{17}$
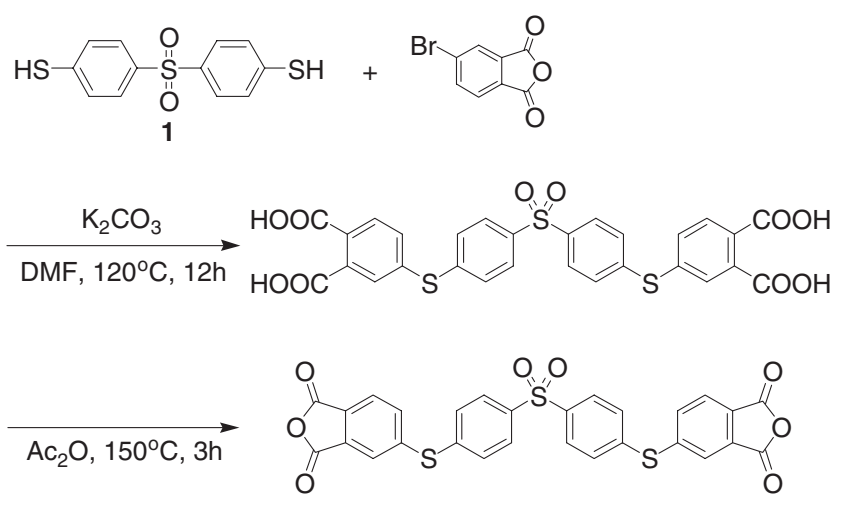

Scheme 1. Synthesis of DPSDA.

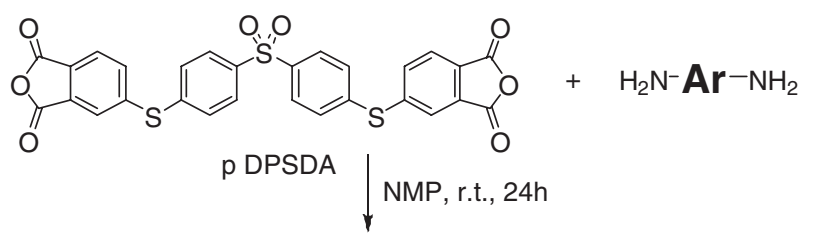<smiles></smiles><smiles>Cc1ccc(Sc2ccc(Sc3ccc(Sc4ccc(C)cc4)cc3)cc2)cc1</smiles><smiles>Cc1ccc(Sc2ccc(Sc3ccc(Sc4ccc(S(=O)(=O)c5ccc(Sc6ccc(C)cc6)c(Sc6ccc(Sc7ccc(C)cc7)cc6)c5)cc4)cc3)cc2)cc1</smiles>

Scheme 2. Synthesis of Pls.

\section{Synthesis of Polyimide}

A series of PIs were synthesized by employing a two-step polycondensation procedure of $p$ DPSDA with three sulfurcontaining diamines via the soluble PAA precursors, followed by thermal imidization at elevated temperatures (Scheme 2). The diamines employed for the polymerization have their own special characteristics. 3SDA containing flexible linear thioether linkages produced PIs with high $n_{\mathrm{av}}$, low $\Delta n$, good transparency, and low $T_{\mathrm{g}}$ at the same time. ${ }^{7}$ APTT possessing higher sulfur contents $(27.7 \mathrm{wt} \%)$ gave the PI with the highest refractive index of 1.7600 while having high transparency and a low birefringence. ${ }^{9}$ On the other hand, BADPS contains both thioether and sulfonyl linkages; thus, the optical transparency is improved because of the reductions in the chain-chain CT interaction in the PIs caused by the incorporation of bulky sulfonyl moiety and the meta-substituted structures. ${ }^{18}$

PAAs with inherent viscosities in the range of 0.27$0.37 \mathrm{dL} / \mathrm{g}$ were prepared easily (Table I). Flexible and tough PI films were obtained by heating the corresponding PAAs cast onto a quartz substrate (diameter, $10 \mathrm{~cm}$ ) up to $300^{\circ} \mathrm{C}$ in nitrogen, followed by immersion in warm water. The structure of PIs was characterized by IR and elemental analysis. The FTIR spectra of $p$ DPSDA/3SDA show characteristic absorptions due to the imide ring at $1780\left(v_{\mathrm{as}, \mathrm{C}=\mathrm{O}}\right), 1720\left(v_{\mathrm{s}, \mathrm{C}=\mathrm{O}}\right)$, and $1387 \mathrm{~cm}^{-1}\left(v_{\mathrm{as}, \mathrm{C}-\mathrm{N}}\right)$ (Figure 1). The absorption due to $\mathrm{C}-\mathrm{S}$ stretching of an Ar-S-Ar unit is also observed at $1083 \mathrm{~cm}^{-1}$ (indicated by asterisks in the spectra). Furthermore, the structures of the PIs were confirmed by elemental analysis. 
Table I. Inherent viscosities of PAAs

\begin{tabular}{llll}
\hline & $\mathrm{Pl}-1$ & $\mathrm{Pl}-2$ & $\mathrm{Pl}-3$ \\
\hline$[\eta]_{\mathrm{inh}}{ }^{\mathrm{a}}(\mathrm{dL} / \mathrm{g})$ & 0.31 & 0.27 & 0.37 \\
\hline
\end{tabular}

a Measured at a concentration of $0.5 \mathrm{~g} / \mathrm{dL}$ in NMP at $30^{\circ} \mathrm{C}$.

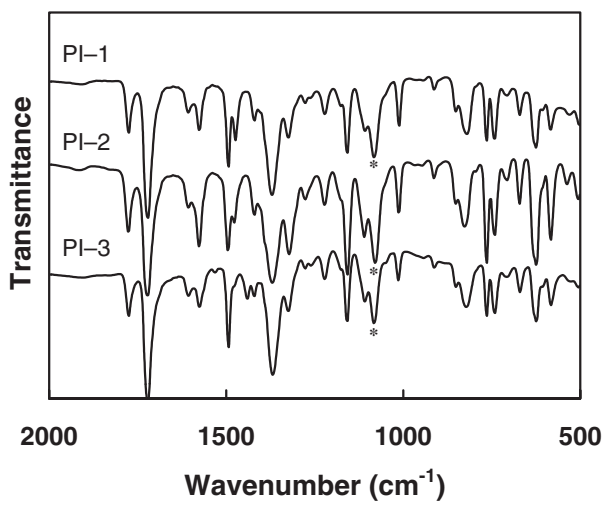

Figure 1. FT-IR spectra of the PI films.

Table II. Thermal properties of PI films

\begin{tabular}{clccc}
\hline & Film color ${ }^{\mathrm{a}}$ & $\begin{array}{c}T_{\mathrm{d}}{ }^{\mathrm{b}} \\
\left({ }^{\circ} \mathrm{C}\right)\end{array}$ & $\begin{array}{c}T_{\mathrm{g}}(\mathrm{DSC})^{\mathrm{c}} \\
\left({ }^{\circ} \mathrm{C}\right)\end{array}$ & $\begin{array}{c}T_{\mathrm{g}}(\mathrm{DMA})^{\mathrm{c}} \\
\left({ }^{\circ} \mathrm{C}\right)\end{array}$ \\
\hline pDPSDA/3SDA (PI-1) & pale-yellow & 501 & 208 & 202 \\
pDPSDA/BADPS (PI-2) & pale-yellow & 491 & 238 & 234 \\
pDPSDA/APTT (PI-3) & pale-yellow & 474 & 235 & 233 \\
ref- $m$ DPSDA/3SDA & pale-yellow & 490 & 178 & 174 \\
ref- $m$ DPSDA/BADPS & pale-yellow & 494 & 207 & 203 \\
ref- $m$ DPSDA/APTT & pale-brown & 498 & 205 & 205 \\
\hline
\end{tabular}

${ }^{\mathrm{a}}$ Color at the thickness of approximately $10 \mu \mathrm{m} .{ }^{\mathrm{b}} T_{5 \%}$ : temperatures at $5 \%$ weight loss. ${ }^{c} T_{\mathrm{g}}$ : glass transition temperatures.

\section{Thermal Properties of PIs}

The thermal properties of the PIs were investigated by TGA, DSC, and DMA measurements. The results are summarized in Table II, where the corresponding PIS from $m$ DPSDA are listed for the comparison of these properties. The 5\% weight loss temperatures $\left(T_{\mathrm{d}}{ }^{5}\right)$ in nitrogen were observed at 470 $500{ }^{\circ} \mathrm{C}$, indicating the thermal stability of sulfur-containing PIs is a little low compared to that of their common analogs as reported in the literature. ${ }^{19}$ The glass transition temperatures $\left(T_{\mathrm{g}}\right)$ were 208,238 , and $235^{\circ} \mathrm{C}$ for PI-1, PI-2, and PI-3, respectively. These results indicate the PIs derived from $p$ DPSDA have nearly $30^{\circ} \mathrm{C}$ higher $T_{\mathrm{g}} s$ than those of the corresponding PIs derived from $m$ DPSDA because a $p$ substituted sulfonyl linkage gives the more rigid PIs compared to the PIs having $m$-substituted sulfonyl linkage, which decreases the mobility of polymer chains at elevated temperatures.

Figure 2 shows the typical DMA curves of the PIs measured at the loading frequency of $1 \mathrm{~Hz}$. The relationships between the temperatures and the storage modulus $\left(E^{\prime}\right)$, loss modulus $\left(E^{\prime \prime}\right)$, and $\tan \delta$ of the polymers are illustrated, respectively. The polymers retain their mechanical properties up to about $202{ }^{\circ} \mathrm{C}$ for PI-1, $234^{\circ} \mathrm{C}$ for PI-2, and $233{ }^{\circ} \mathrm{C}$ for PI-3. The modulus of
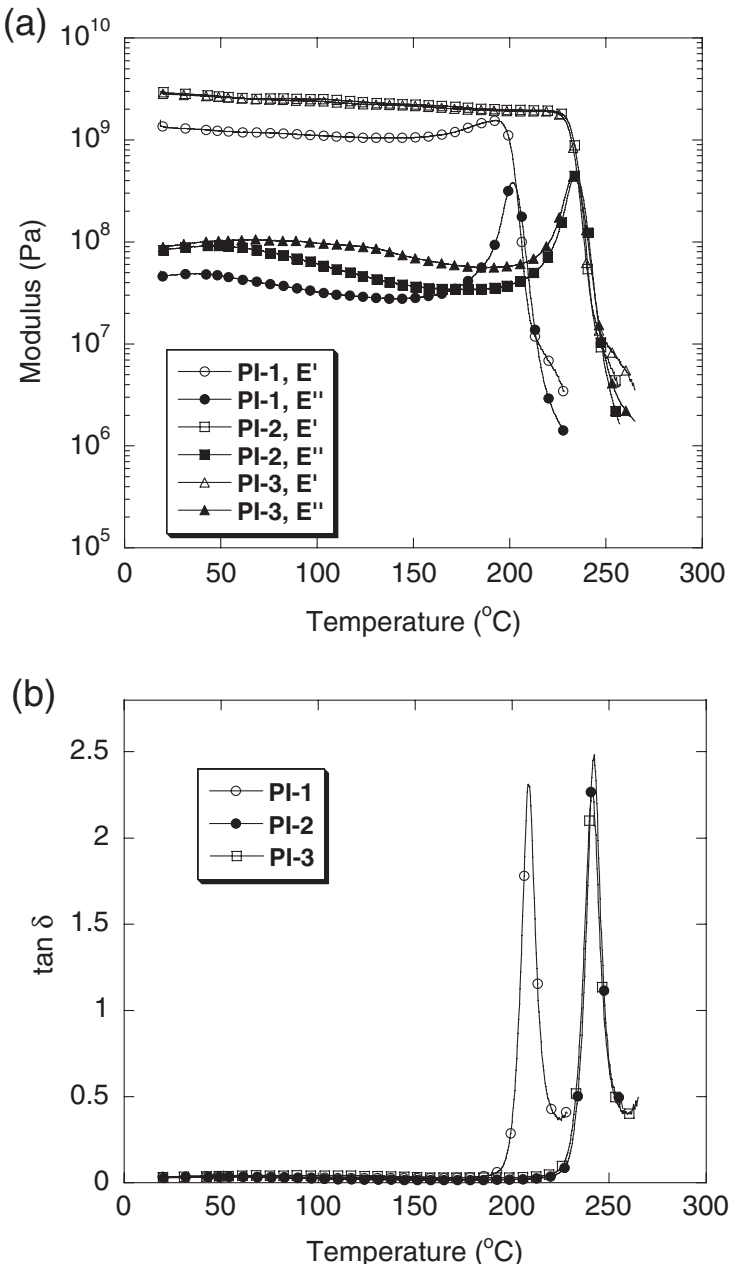

Figure 2. DMA curves of the $\mathrm{PI}$ films $\left(1 \mathrm{~Hz}, 2^{\circ} \mathrm{C} / \mathrm{min}\right.$, in air). (a) Storage modulus $E^{\prime}$ and loss modulus $E^{\prime \prime}$; (b) $\tan \delta$.

the polymers dropped dramatically at $T_{\mathrm{g}}$. The $T_{\mathrm{g}}$ values determined as the peak temperatures of the $E^{\prime \prime}$ plots are in good agreement with those determined by DSC. The polymers show the initial storage modulus of $1.6 \mathrm{GPa}$ for PI-1, 3.0 GPa for PI-2, and 2.9 GPa for PI-3, indicating the good mechanical properties of the polymers.

\section{Optical Properties of PIs}

The UV-vis optical transmission spectra of the PI films with thicknesses of 7.0-9.6 $\mu \mathrm{m}$ are shown in Figure 3 (top), and the optical data are summarized in Table III. The cut-off wavelengths $\left(\lambda_{\text {cutoff }}\right)$, which are determined by the wavelengths corresponding to the intersection points of the line tangent to the UV-vis curves, are in the range of $373-390 \mathrm{~nm}$. The transmittances of the films measured at $450 \mathrm{~nm}$ are entirely higher than $85 \%$, which is significantly higher than that of the reference PI (ref-PI) derived from 4,4'-[ $p$-thiobis(phenylenesulfanyl)]diphthalic anhydride (3SDEA) and 3 SDA. $^{7}$ This high transparency is attributable to the reduction of both the contiguous interaction between (amine) phenyl donor/imide acceptor fragments and the formation of a "mixed layer" 

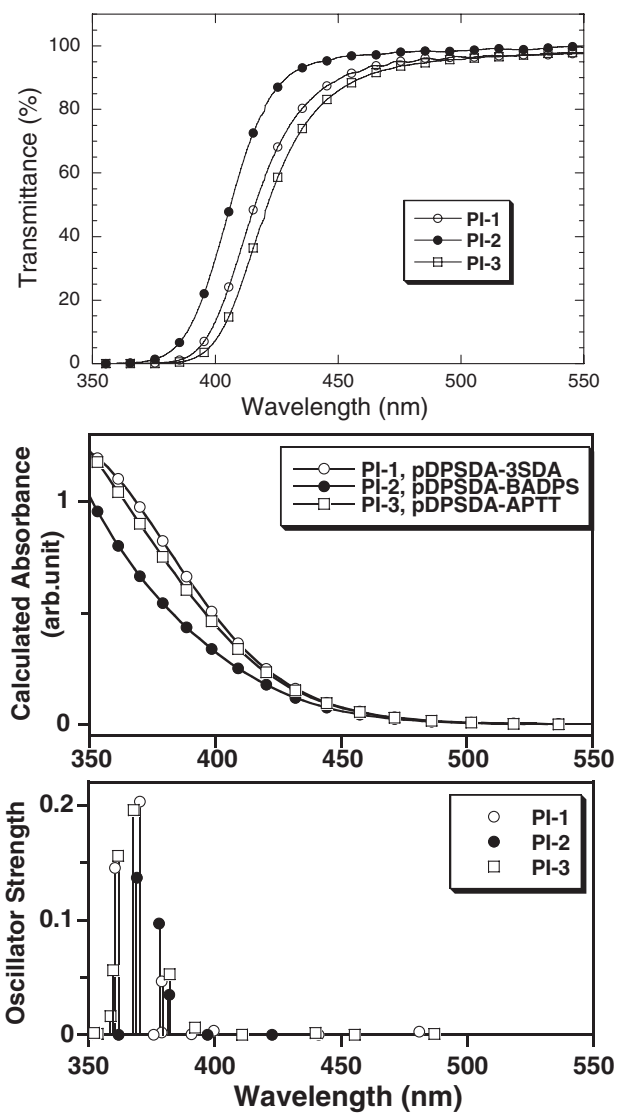

Figure 3. Experimental UV-vis transmission and calculated absorption spectra of the PI films.
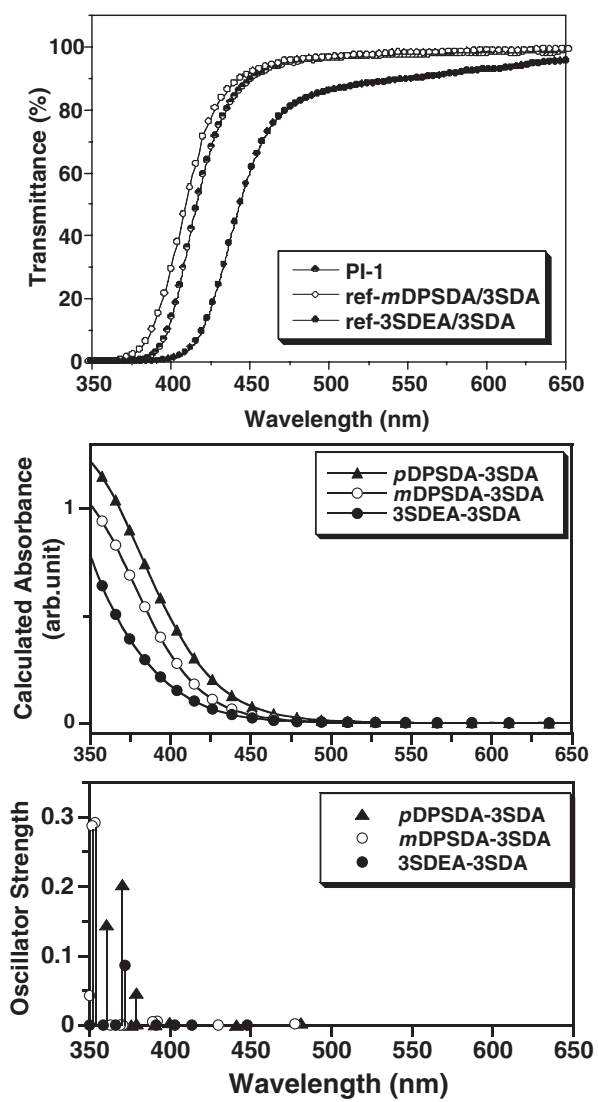

Figure 4. Experimental UV-vis transmission and calculated absorption spectra of PIs from $p$ DPSDA, mDPSDA, and 3SDA.

Table III. Optical properties of PI films

\begin{tabular}{ccccccccc}
\hline & $\begin{array}{c}S \mathrm{c}^{\mathrm{a}} \\
(\mathrm{wt} \%)\end{array}$ & $\begin{array}{c}T_{450 \mathrm{~nm}}{ }^{\mathrm{b}} \\
(\%)\end{array}$ & $\begin{array}{c}d^{\mathrm{c}} \\
(\mu \mathrm{m})\end{array}$ & $n_{\mathrm{TE}}{ }^{\mathrm{d}}$ & $n_{\mathrm{TM}^{\mathrm{d}}}$ & $n_{\text {av }}{ }^{\mathrm{d}}$ & $\Delta n^{\mathrm{d}}$ & $n_{\text {ccal }}{ }^{\mathrm{e}}$ \\
\hline PI-1 & 19.8 & 90 & 7.4 & 1.7340 & 1.7275 & 1.7319 & 0.0065 \\
PI-2 & 19.2 & 96 & 7.3 & 1.7191 & 1.7124 & 1.7169 & 0.0066 & 1.7456 \\
PI-3 & 22.4 & 86 & 11.2 & 1.7450 & 1.7357 & 1.7420 & 0.0093 & 1.7589 \\
ref-mDPSDA/3SDA & 19.8 & 92 & 5.4 & 1.7329 & 1.7269 & 1.7309 & 0.0059 & 1.7398 \\
ref-mDPSDA/BADPS & 19.2 & 95 & 3.6 & 1.7182 & 1.7121 & 1.7162 & 0.0061 & 1.7095 \\
ref-mDPSDA/APTT & 22.4 & 87 & 4.8 & 1.7453 & 1.7388 & 1.7432 & 0.0065 \\
ref-3SDEA/3SDA & 20.5 & 60 & 9.3 & 1.7505 & 1.7437 & 1.7482 & 0.0068 & 1.7537 \\
\hline
\end{tabular}

a Sulfur content. ${ }^{\mathrm{b}}$ Transmittance at the wavelength of $450 \mathrm{~nm}$. ${ }^{\mathrm{C}}$ Film thickness for refractive index measurement. ${ }^{\mathrm{d}}$ Measured at $632.8 \mathrm{~nm}$, see Measurements. ${ }^{e}$ Calculated refractive index, see Calculation.

configuration between the (amine) phenyl and imide groups of neighboring chains by the bulky sulfonyl groups. The calculated UV-vis absorption spectra of the PIs are shown in Figure 3 (middle) with the stick spectra of oscillator strength for one-electron transitions (bottom). The higher transparency of PI-2 in the 400-450 $\mathrm{nm}$ range of transmission spectra is well reproduced by the calculation. Since the calculated ionization potential of BADPS (7.08 eV) is significantly larger than those of 3SDA $(6.63 \mathrm{eV})$ and APTT $(6.73 \mathrm{eV})$, the one-electron transition mainly originating from $\mathrm{HOMO} \rightarrow$ LUMO for PI-2 appears at much shorter wavelength $(422 \mathrm{~nm})$ than those for PI-1 $(481 \mathrm{~nm})$ and PI-3 $(487 \mathrm{~nm})$. In addition, the oscillator strengths of the major $\pi-\pi^{*}$ transitions for PI-2 appearing around 360-380 nm are smaller than those of PI-1 and PI-3. These facts clearly indicate that the incorporation of sulfonyl linkage to the diamine moiety improves the optical transparency. The higher transmittance in such short wavelength region is quite important for the optical applications using the whole range of visible light.

As described in the Introduction, a para-substituted sulfony linkage effectively increases the electron-accepting ability of an imide ring compared to a meta-substituted linkage, which is expected to decrease transparency. However, the transparency between the PI-1 film and the ref- $m$ DPSDA/3SDA PI film is almost same as shown in the UV-vis spectra (Figure 4, top). This fact is also supported by the very close values of the 
transmittance at $450 \mathrm{~nm}\left(T_{450 \mathrm{~nm}}\right)$ between the corresponding para- and meta-substituted isomers, i.e., 90 and 92\% for 3SDAderived, 96 and $95 \%$ for BADPS-derived, and 86 and $87 \%$ for APTT-derived PIs. The calculated UV-vis absorption spectra of the PIs are shown in Figure 4 (middle) with the stick spectra of oscillator strength for one-electron transitions (bottom). Firstly, the calculation indicates that ref-3SDEA/3SDA PI may show the lowest absorption at the shorter wavelengths. However, as shown in Figure 4, this PI exhibits significant coloration in the experimental spectra with the $T_{450 \mathrm{~nm}}$ value of $60 \%$, which is attributable to the enhanced inter-molecular interactions caused by the consecutive thiother substituents. The thioether linkage is more likely to form well-packed intermolecular orderings stabilized by the CTC formation in contrast to sulfonyl linkage. Secondly, the calculated absorbance of $m$ DPSDA-derived PI in the shorter wavelength region is slightly lower than that of $p$ DPSDA-derived PI, which coincides well with the experimental spectra. Since the calculated electron affinity of $m$ DPSDA $(2.03 \mathrm{eV})$ is slightly smaller than those of $p$ DPSDA $(2.21 \mathrm{eV})$, the one-electron transition mainly originating from $\mathrm{HOMO} \rightarrow$ LUMO for $m$ DPSDA-3SDA appears at shorter wavelength $(477 \mathrm{~nm})$ than those for $p$ DPSDA-3SDA $(481 \mathrm{~nm})$. In addition, the oscillator strengths of the major $\pi-\pi^{*}$ transitions appearing around 360 $380 \mathrm{~nm}$ in the former are smaller than those of the latter. These facts clearly indicate that the incorporation of meta-linkage to the dianhydride moiety improves the optical transparency. The agreement between the experimental and calculated absorption edges for the para- and meta-DPSDA-derived PIs also demonstrates the limited influence of the intermolecular interactions in these PIs. These behaviors may be explained as follows; the sulfonyl group is far from the imide group and does not influence the electron-accepting ability of an imide ring. The contiguous interaction between (amine) phenyl donor/imide acceptor fragments and the formation of a "mixed layer" configuration are effectively reduced even by the parasubstituted sulfony linkage.

As listed in Table III, the in-plane $\left(n_{\mathrm{TE}}\right)$ and out-of-plane $\left(n_{\mathrm{TM}}\right)$ refractive indices of the PI films ranged from 1.71911.7450 and $1.7124-1.7357$, respectively. The fact that the $n_{\mathrm{TE}}$ values of PI films are slightly higher than $n_{\mathrm{TM}}$ ones reflects the higher chain orientation parallel to the film plane. The average refractive indices $\left(n_{\mathrm{av}}\right)$ estimated from the $n_{\mathrm{TE}}$ and $n_{\mathrm{TM}}$ values range between $1.7169-1.7420$ in the order of PI-3 (1.7420) < PI-1 (1.7319) < PI-2 (1.7169). This trend agrees with that of sulfur content, though it has been established that the refractive indices of PIs are affected by several factors including molecular geometry, molecular polarizability, and chain linearity or flexibility of polymer backbone, and degree of molecular packing. ${ }^{10}$ In addition, the trend is consistent with the calculated refractive indices $\left(n_{\text {cal }}\right)$ using DFT. The comparison among the $n_{\mathrm{av}}$ values for PI-1, PI-2, and ref-PI indicates that the substitution of one and two sulfonyl linkages for thioether linkages in the main chain reduce the $n_{\mathrm{av}}$ by 0.0163 (ref-PI $\rightarrow$ PI-1) and 0.0313 (ref-PI $\rightarrow$ PI-2), respectively. These systematic decreases are essentially attributable to the lower polarizability per unit volume of sulfonyl linkage than that of -S- linkage. As discussed in our previous report, ${ }^{11}$ the two oxygen atoms in sulfonyl linkage significantly increase the molecular volume of the linkage and reduce the content of polarizable sulfur atoms in the PIs. In addition, sulfonyl linkage renders reduction of the intermolecular CTC formation and the electron-donating ability of the diamine. A clear trade-off relation exists between the refractive indices and the optical transparency as seen in Figure 4 and Table III. Higher sulfonyl content improves optical transparency but also leads to a lower refractive index. In contrast, the introduction of thianthrene ring (PI-3) significantly increase the values of sulfur content (Sc) and $n_{\mathrm{av}}$, but they slightly deteriorate the optical transparency as mentioned above. The coefficients of molecular packing $\left(K_{\mathrm{p}}\right)$ estimated from the calculated molecular polarizabilities and experimental $n_{\mathrm{av}}$ values are 0.5916, 0.5931, 0.5899 for PI-1, PI-2, PI-3, respectively. It is interesting to note that the highest $K_{\mathrm{p}}$ value was obtained with PI-2 containing two sulfonyl linkages in the main chain, which demonstrates that the sulfonyl linkage does not reduce the degree of molecular packing but does the polarizability per volume. The same trend was also observed for the PIs derived from $m$ DPSDA. The highest $n_{\text {av }}$ observed for PI-3 (1.7420) is lower than that of ref3SDEA/3SDA PI (1.7482), but the much better transparency of the former (pale yellow for a $10 \mu \mathrm{m}$-thick film) than the latter (brown color for the same thickness) should be useful for certain optical applications utilizing the whole range of visible wavelengths (e.g., 400-800 nm).

Both of the flexible sulfone and thioether linkages in the molecular chains of the PIs (PI-1 to PI-3) including the other reference PIs endow them with low $\Delta n$ in the range of $0.0061-$ 0.0093. Note that the PI containing a planar and two-dimensionally polarizable ring of thianthrene (PI-3) also exhibits a significantly small value of $\Delta n$. This indicates that the introduction of sulfonyl linkage is an effective way to prevent the in-plane orientation of PI chains. These optically isotropic PI films are very desirable for advanced optical fabrications in micro-optics and optical waveguide and circuit applications.

\section{CONCLUSIONS}

Novel PIs were prepared from $p$ DPSDA and various sulfurcontaining diamines. The PIs derived from $p$ DPSDA exhibited higher $T_{\mathrm{g}} \mathrm{s}$ than those of their analogous $m$ DPSDA-based PIs due to their rigid polymer chains. The PI films exhibited good optical transmittances exceeding $85 \%$ at $450 \mathrm{~nm}$ and showed pale-yellow color for the thickness of $c a$. $10 \mu \mathrm{m}$ due to the existence of the para-substituted bulky sulfonyl moieties. The transparency of the PI-1 films derived from $p$ DPSDA is almost same as that of the PI film derived from $m$ DPSDA. The average refractive indices $\left(n_{\mathrm{av}}\right)$ measured at $632.8 \mathrm{~nm}$ range from 1.7169 to 1.7420 depending on the different sulfur contents of the PIs, and are almost same those of the PIs derived from $m$ DPSDA. In the same way of $m$ DPSDA-based PIs, a clear trade-off relation exists between the refractive indices and the optical transparency; a higher sulfonyl content improves the 
transparency but lowers the refractive index. In addition, very small birefringence $(\Delta n)$ of $0.0065-0.0093$ was obtained for the PIs. The small difference in the optical properties between the $p$ DPSDA-based and $m$ DPSDA-based PIs can be explained by the nature of bulky sulfonyl linkage, which reduces both the intra molecular interaction of donor and acceptor moieties in the PIs and the intermolecular interaction between the PI chains. The optical properties of proposed PIs are sufficiently high to meet the requirements of optical fabrications. The good combined properties of the present PIs make them good candidates for advanced applications.

Received: December 11, 2007 Accepted: January 23, 2008 Published: March 12, 2008

\section{REFERENCES}

1. "Polyimides: Fundamentals and Applications," M. K. Ghosh and K. L. Mittal, Ed. Marcel Decker, New York, 1996.

2. J. Nakai and T. Aoki, U. S. Patent 7087945 (2006).

3. C.-C. Chang and W.-C. Chen, J. Polym. Sci., Part A: Polym. Chem., 39, 3419 (2001).

4. C.-C. Chang and W.-C. Chen, Chem. Mater., 14, 4242 (2002).
5. C.-M. Chang, C.-L. Chang, and C.-C. Chang, Macromol. Mater. Eng., 291, 1521 (2006)

6. G. Liu, Y. Nakamura, Y. Shibasaki, S. Ando, and M. Ueda, Polym. J., 39, 543 (2007).

7. G. Liu, Y. Nakamura, Y. Shibasaki, S. Ando, and M. Ueda, J. Polym. Sci., Part A: Polym. Chem., 45, 5606 (2007).

8. G. Liu, Y. Nakamura, Y. Shibasaki, S. Ando, and M. Ueda, Macromol. Chem. Phys., in press.

9. G. Liu, Y. Nakamura, Y. Shibasaki, S. Ando, and M. Ueda, Macromolecules, 40, 4614 (2007).

10. S. Ando, T. Matsuura, and S. Sasaki, Polym. J., 29, 69 (1997).

11. G. Liu, Y. Nakamura, Y. Suzuki, Y. Shibasaki, S. Ando, and M. Ueda, Macromolecules, 40, 7902 (2007).

12. J. Yan, Z. Wang, L. Gao, and M. Ding, Polymer, 46, 7678 (2005).

13. J. M. Salley and C. W. Frank, "Polyimides Fundamentals and Applications" M. K. Ghosh and K. L. Mittal, Ed., Marcel Decker, New York, 1996, p 288.

14. Y. Ding and A. S. Hay, Macromolecules, 29, 6386 (1996).

15. S. Ando, T. Fujigaya, and M. Ueda, Jpn. J. Appl. Phys. 41, L105 (2002).

16. Y. Terui and S. Ando, J. Photopolym. Sci. Technol., 18, 337 (2005).

17. T. Sugioka and A. S. Hay, J. Polym. Sci., Part A: Polym. Chem., 39, 1040 (2001).

18. K. St. Clair, T. L. Clair, and W. P. Winfree, Proc. ACS Polym. Mater. Sci. Eng., 59, 28 (1988).

19. R. J. Nussbaumer, W. R. Caseri, O. Smith, and T. Tervoort, Macromol. Mater. Eng., 288, 44 (2003). 